\title{
Gênero e cotidiano em uma propriedade rural em Altamira, Pará: Uma abordagem por meio de objetos
}

Gender and everyday life in a rural property in Altamira, State of Pará: an approach through objects

\section{Paula Lacerda}

\section{(2) OpenEdition Journals}

\section{Edição electrónica}

URL: http://journals.openedition.org/aa/3035

DOI: 10.4000/aa.3035

ISSN: 2357-738X

\section{Editora}

Programa de Pós-Graduação em Antropologia Social (UnB)

\section{Edição impressa}

Data de publição: 1 julho 2018

Paginação: 317-326

ISSN: 0102-4302

\section{Refêrencia eletrónica}

Paula Lacerda, «Gênero e cotidiano em uma propriedade rural em Altamira, Pará: Uma abordagem por meio de objetos», Anuário Antropológico [Online], v.43 n.1 | 2018, posto online no dia 26 maio 2019, consultado o 28 abril 2021. URL: http://journals.openedition.org/aa/3035 ; DOI: https://doi.org/ 10.4000/aa.3035

\section{@) $\Theta \Theta \Theta$}

Anuário Antropológico is licensed under a Creative Commons Atribuição-Uso Não-Comercial-Proibição de realização de Obras Derivadas 4.0 International. 


\section{Gênero e cotidiano em uma propriedade rural em Altamira, Pará: uma abordagem por meio de objetos}

Paula Lacerda

UERJ

Em 1983, o Instituto Nacional de Colonização e Reforma Agrária (INCRA) demarcou uma área de cerca de 32 mil hectares para o Projeto de Assentamento Assurini, no município de Altamira, estado do Pará. Este assentamento foi um dos vários implantados em Altamira, após a abertura da Rodovia Transamazônica, inaugurada em 1972. Atualmente, residem cerca de 500 famílias nesses lotes, a maioria oriunda do Ceará e do Rio Grande do Norte.

Juarez Gomes Pessoa é o proprietário e morador do lote fotografado. Ele nasceu em 1954, no interior do Ceará, em uma família de agricultores. Chegou em Altamira nos anos 70. Desde o início de minha pesquisa na cidade, em 2009, frequento o lote do Seu Juarez, distante poucos quilômetros do início da estrada Transassurini, onde se chega após atravessar o rio Xingu e contornar uma ilha, de balsa. Seu Juarez é marido de Rosa Pessoa, minha interlocutora de pesquisa há dez anos. Dona Rosa, como eu a chamo, é uma liderança importante em Altamira e mora na cidade. Ela vai ao lote ocasionalmente, pois gosta de cozinhar no fogão de barro, tomar banho no igarapé e andar pela propriedade que ajudou a construir. Sua irmã, Raimunda, quase sempre acompanha Dona Rosa nas visitas ao lote do cunhado, quando colhe frutas para seu consumo, ajuda na cozinha, descansa, trabalha. As visitas têm, geralmente, curta duração, não se prolongando por mais que três dias.

Nas imagens que seguem, procurei registrar o cenário rural de uma localidade amazônica a partir da morada do Seu Juarez. Registrei objetos e cenas que mostram o cotidiano de alguém que vive, na maior parte do tempo, sozinho, se servindo da casa como morada, depósito, garagem. Em alguns momentos, esse cotidiano é atravessado pela (nossa) presença feminina, que produz outras composições na cena cotidiana, o que busquei registrar também. Ao registrar serras, cascos de animais, motocicleta, roupas próprias para a lida com a roça, vasilhas e alimentos, não pretendo sugerir qualquer distinção de gênero intrín- 
seca entre os objetos. Ao contrário, argumento que é na dimensão situacional que eles adquirem gênero, e o aspecto temporalmente marcado da visita deixa essa característica mais clara.

Ao fotografar, privilegiei o ponto de vista zenital (ou plongê absoluto) e o formato $1 \mathrm{x} 1$, visando apresentar uma perspectiva pouco comum, provocando assim um estranhamento e conferindo destaque à dimensão de conjunto que objetos, formas e cores adquirem, ao serem justapostos. Em outras imagens, também em formato $1 \mathrm{x} 1$, utilizei o ponto de vista frontal para destacar paredes, que como mesas e outras superfícies planas, expõem objetos como roupas, pedaço de espelho, restos de embalagem. Essas fotografias foram combinadas a outras, em proporção 2x3, que retratam as pessoas em interação com o espaço. As imagens foram capturadas em 2014 e 2016.

Crédito das imagens: Paula Lacerda, Altamira (PA), 2014 e 2016. 


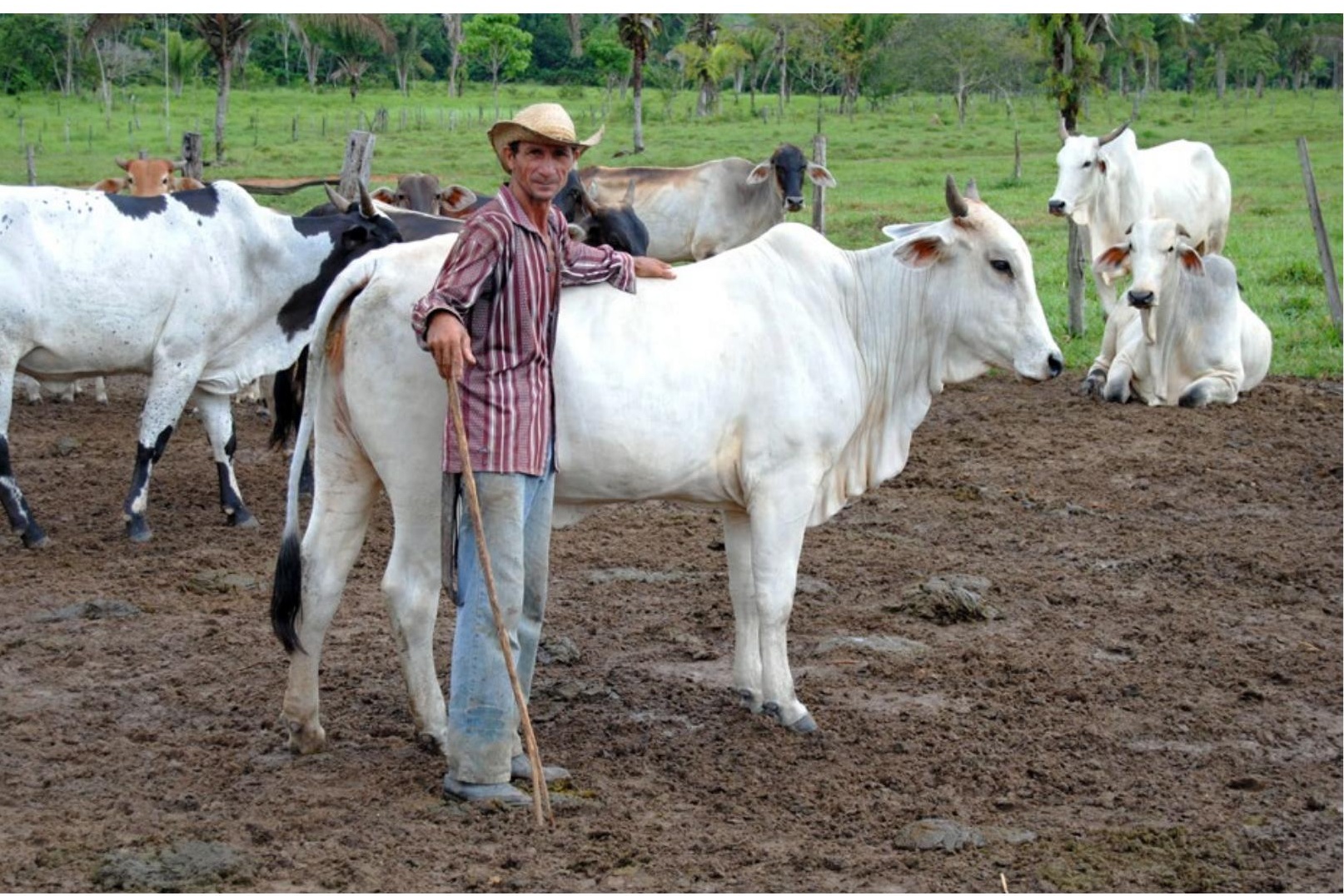

Seu Juarez mora sozinho no lote em que cria cerca de 100 cabeças de gado. Ocasionalmente, contrata força de trabalho adicional, mas não é frequente. Seu Juarez é orgulhoso de ser um "servo de Deus", membro da Congregação Cristã no Brasil. A compra do seu lote é um dos momentos em que a presença de Deus foi fundamental na sua tomada de decisão. Essa fotografia foi registrada a pedido dele, em meio aos seus animais, para que mostrasse aos seus familiares distantes. 

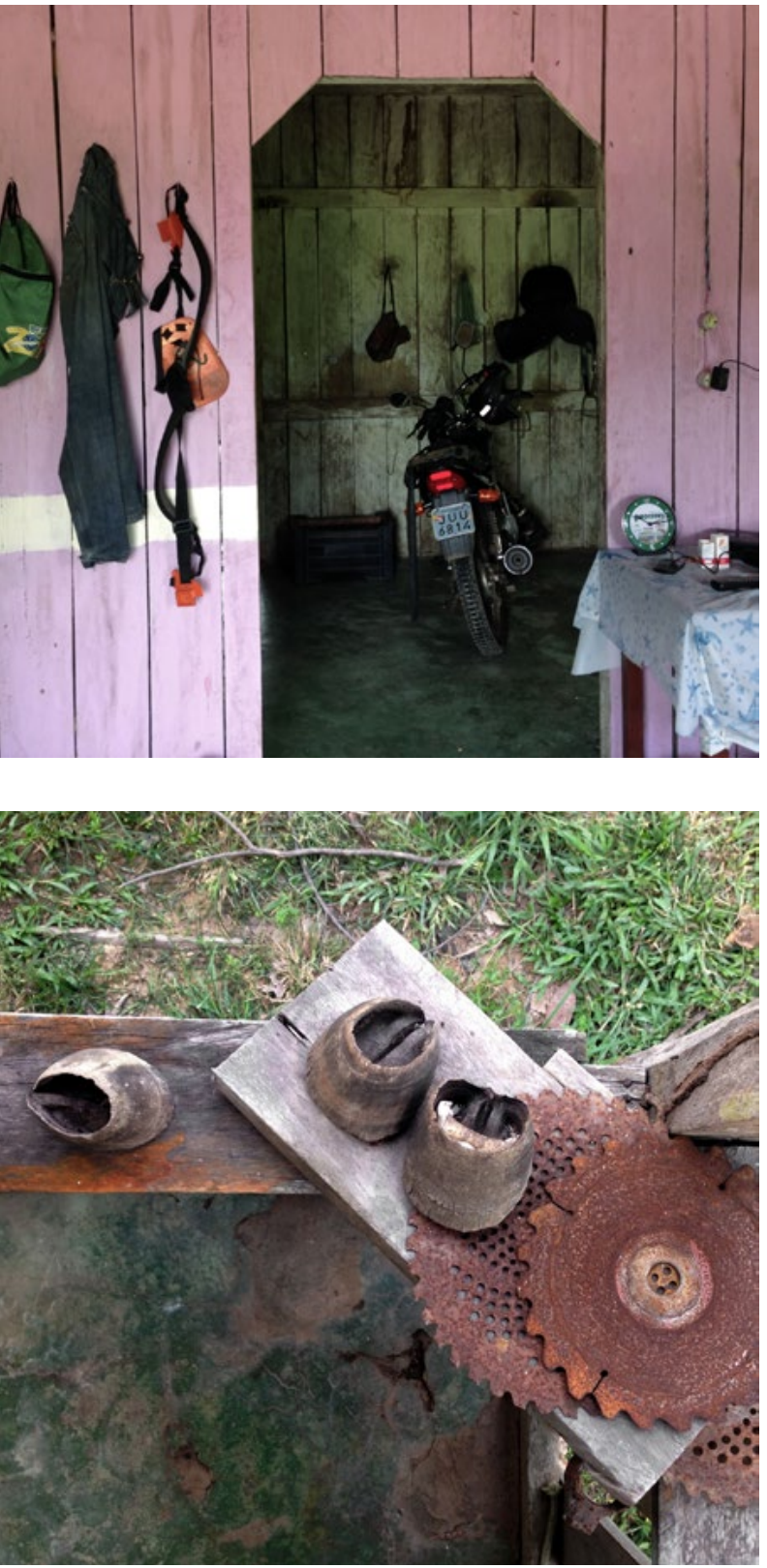

A casa de Seu Juarez é de madeira, como ainda são muitas das casas em Altamira, e na Amazônia de maneira geral. Os poucos e indispensáveis utensílios domésticos se misturam às ferramentas e aos insumos necessários na lida cotidiana com o gado, com as galinhas e com a roça. A moto dentro de casa, as roupas presas em pregos, utensílios para lidar com pesticidas e a pequena mesa com relógio e remédios retratam seu cotidiano. 
Nos últimos anos, são bastante evidentes as transformações em Altamira, especialmente em vista da construção da Usina Hidroelétrica de Belo Monte. No lote de Seu Juarez, a chegada da energia elétrica resultou na aquisição de um refrigerador e de uma máquina de bater açaí, na construção de um banheiro de alvenaria, na instalação de água encanada, além de ligação de pontos de energia em todos os cômodos. O interruptor de instalação recente se justapõe à antiga e empoeirada bacia. O pedaço de espelho grudado na madeira permaneceu no local, apesar de agora haver, no banheiro, um espelho maior. A passagem do tempo se revela também nos adesivos do cuscuz consumido grudados na parede, nos calendários de anos diferentes que se sobrepõem, na casca seca de laranja que ajuda a espantar insetos.
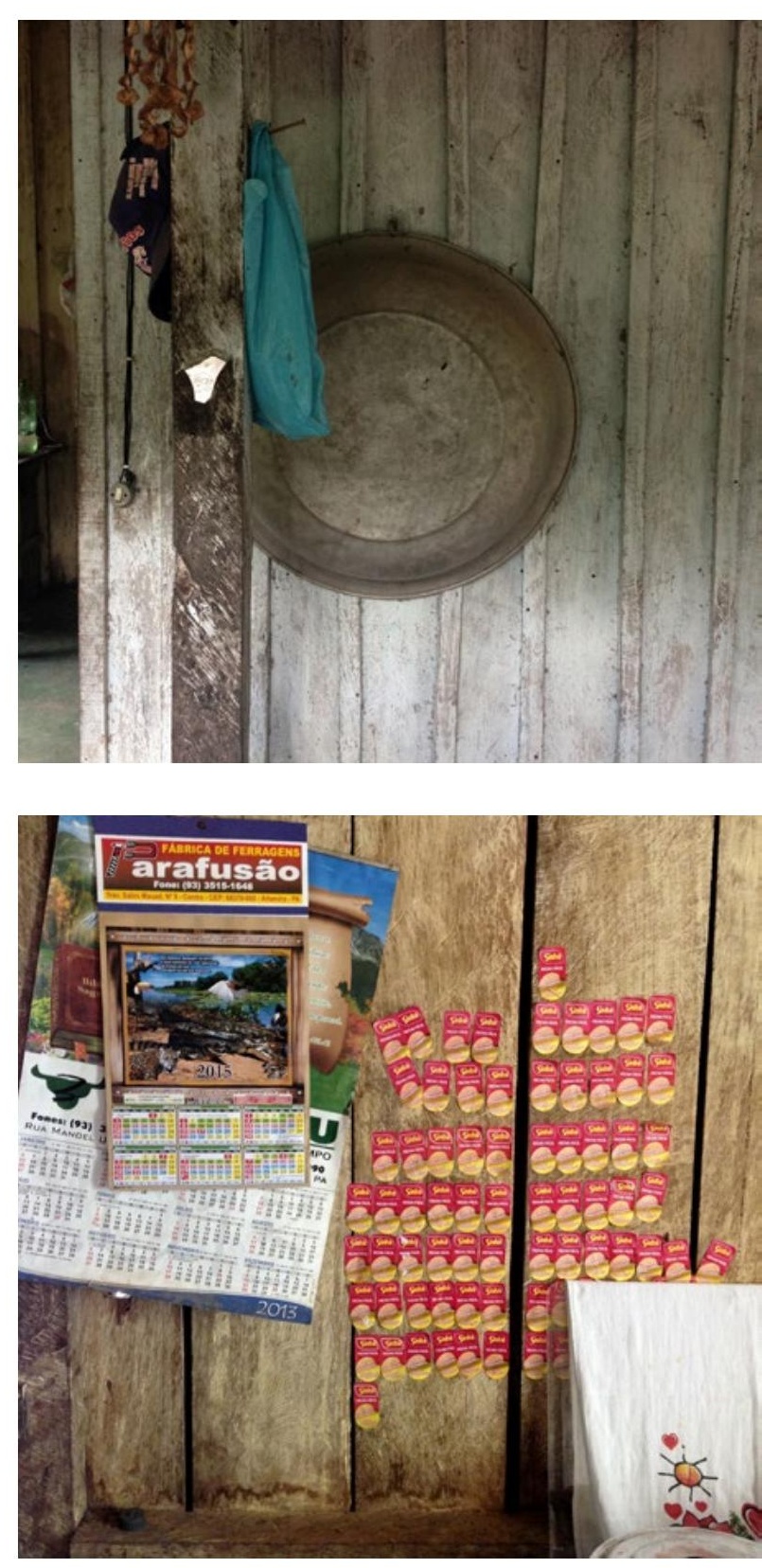


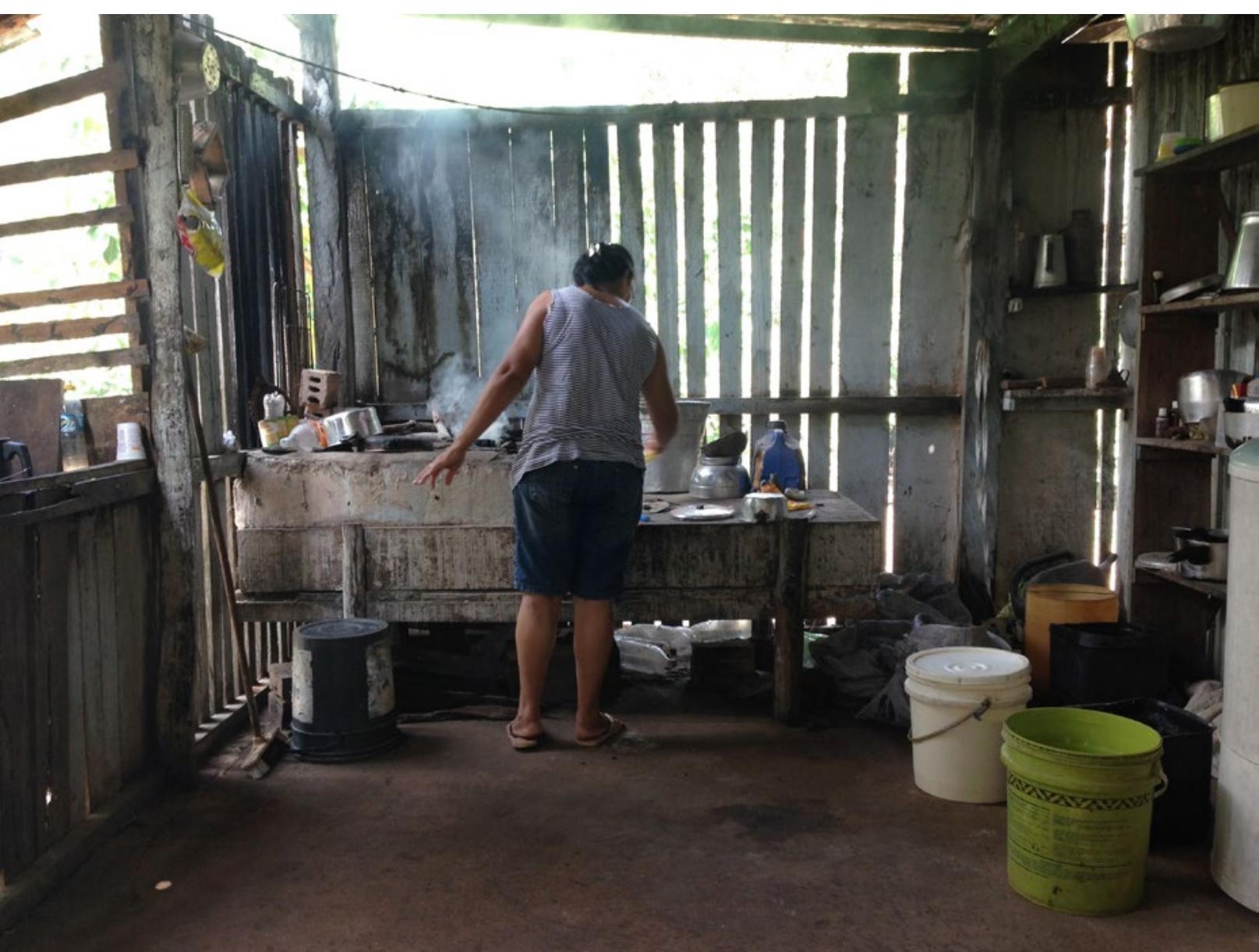


A visita ao lote, nessa ocasião, feita por Dona Rosa, sua irmã Raimunda e eu, é planejada com alguns dias de antecedência, pois é preciso levar muitas coisas. Nesse contexto, certos objetos adquirem gênero, pois não estariam ali se ela - e nós - não estivésse(mos). O bolo na forma, o pano de prato sobre o fogão, a galinha em preparo e o forno de barro em atividade são marcas da presença feminina e eventual no lote.
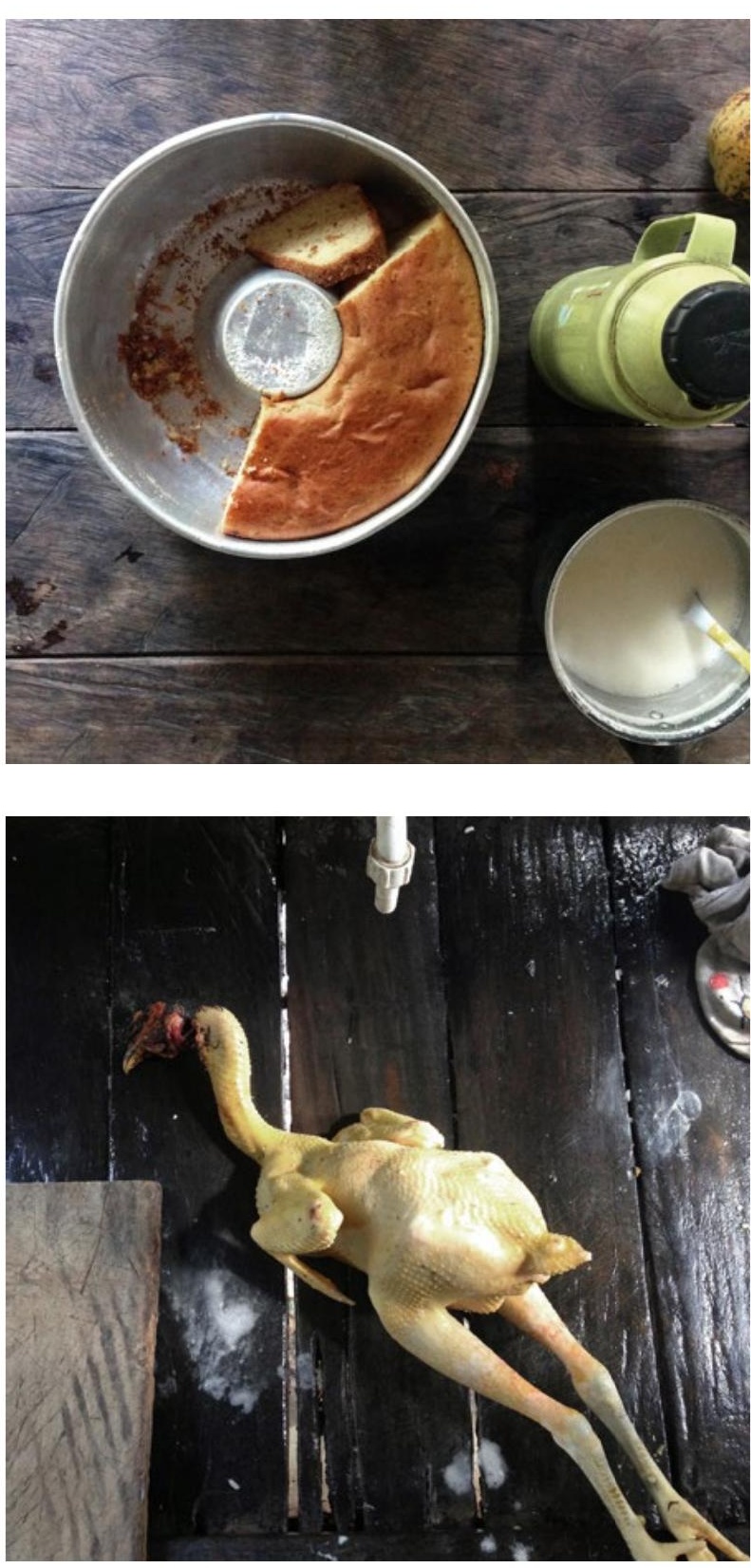


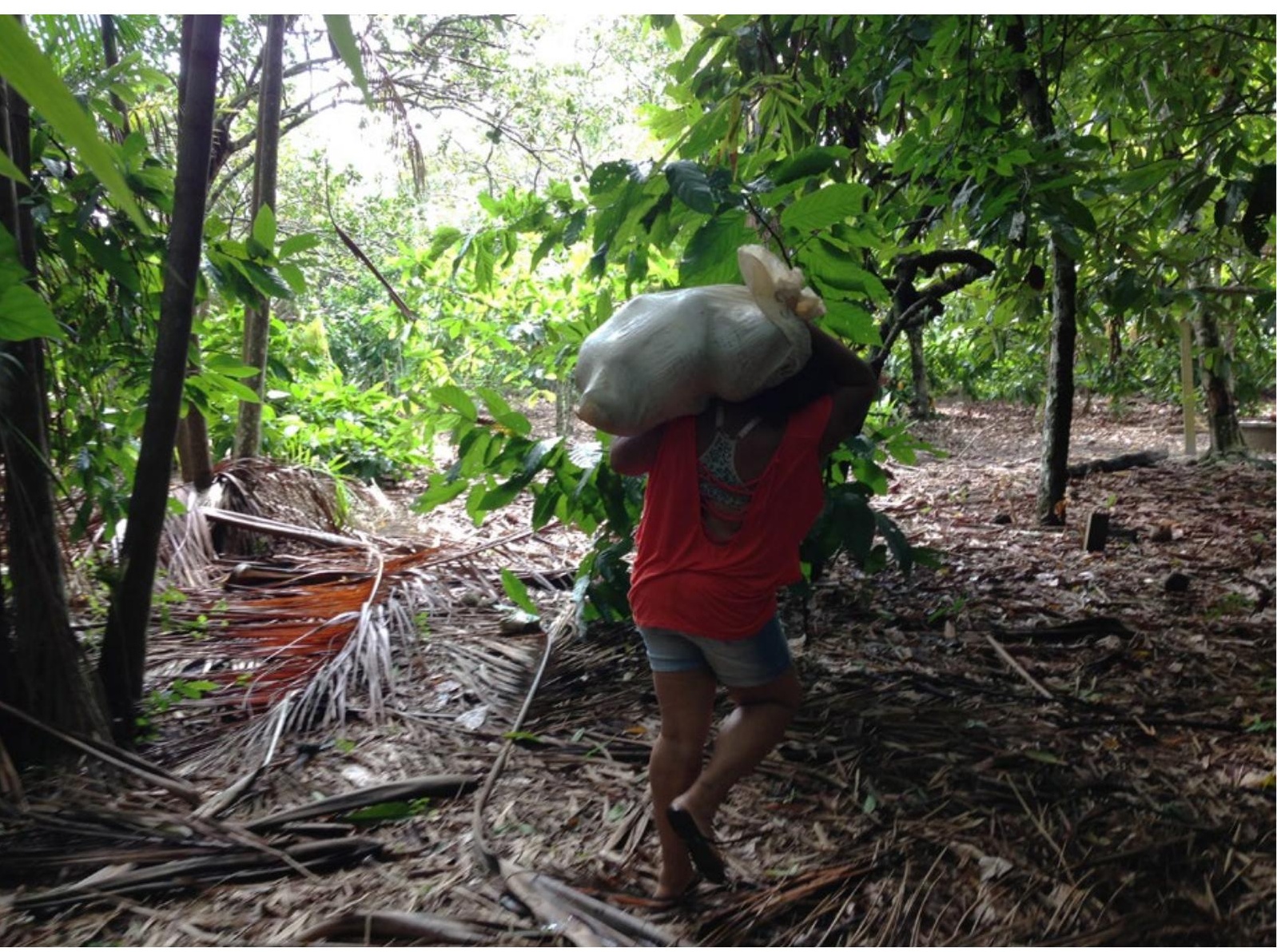

Ao final da visita, levamos de volta coisas que utilizamos, como o galão de água filtrada a forma do bolo, e alimentos colhidos, como cacau, coco, abóbora, cupuaçu. Registrei Raimunda, irmã da Dona Rosa, em movimento, no dia de nossa partida, carregando frutas que ela repartiria com seus filhos e netos.

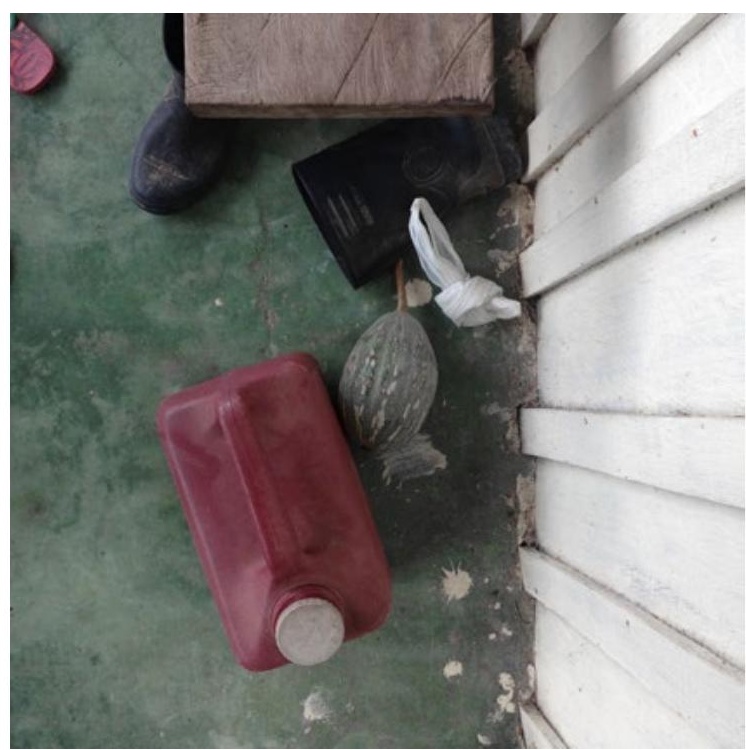


Recebido: 29/03/2018

Aprovado: 06/06/2018

Paula Lacerda é bacharel em Ciências Sociais pela Universidade do Estado do Rio de Janeiro, mestre pelo Instituto de Medicina Social da mesma universidade e doutora em antropologia pelo Programa de Pós-Graduação em Antropologia Social da Universidade Federal do Rio de Janeiro. É professora de Antropologia na Universidade do Estado do Rio de Janeiro e trabalha com os seguintes temas: antropologia do estado, direitos humanos, gênero, sexualidade e Amazônia. Contato: lacerdapaula@gmail.com 
Resumo: $\mathrm{O}$ ensaio fotográfico teve o objetivo de registrar o cotidiano, por meio dos objetos, em uma propriedade rural ("lote") no município de Altamira (PA), Amazônia, evidenciando as conexões em torno do gênero. Argumento que os objetos, junto às pessoas fotografadas, compõem uma narrativa visual sobre os atos de morar, visitar e hospedar. As imagens foram capturadas em 2014 e 2016, período em que as transformações resultantes da construção da Usina Hidroelétrica de Belo Monte eram visíveis e consolidadas.

Palavras-chave: Gênero, Amazônia, UHE Belo Monte.
Abstract: The photographic essay aspired to record the everyday life, through objects, in a rural property ("plot of land") in Altamira district (PA), Amazon, seeking to work on the connections surrounding gender. I argue that the objetcts, along with the people portrayed, compound a visual narrative on the acts of dwelling, visiting and lodging. The pictures were taken in 2014 and 2016, period which the transformations resulting from the construction of the Belo Monte Dam building were already visible and fully consolidated.

Keywords: Gender, Amazon, Belo Monte Dam. 